\title{
Research on the Application of Interactive Design in the Design of Commercial Environment Guide System
}

\author{
Jun Jun Chen ${ }^{1, \text { a }}$ \\ ${ }^{1}$ Harbin University of Commerce, Harbin,Heilongjiang 150028 China \\ a50146051@qq.com
}

Key Words: Interactive Design; Guide System; Business Environment; User Needs; Consumer Experience

\begin{abstract}
As a sign of urbanization development, Guide system has developed more than a few years till today. With the process of urbanization deepening, guide system in the city life has become increasingly important and already integrated into the city's overall cultural atmosphere, becoming an important symbol of the city. With the advent of the mobile Internet era, the large number of touch screen applications increased and people's material life in the experience of the information age has been greatly improved for the development of interactive design provides a broad space. The new design pattern of interactive designism can be applied to the business environment guidance system, which can greatly improve the original navigation system, improve the information, maximize the function and bring more economic benefits for the business.
\end{abstract}

\section{The Definition and Development of Interactive Design}

Interactive design is the behavior of products, the environment and the system. It is also the design and definition of the form elements that convey this behavior. The rapid development of interactive design is accompanied by the emergence and popularization of new media technology. It is derived from the field of industrial design and visual communication design. The purpose of interactive design is to create useful and pleasant behavior, which coincides with the industrial design. Similarly, interactive design and industrial design are cross-disciplines, covering engineering, aesthetics and marketing of these disciplines.

\section{The Law of Interaction Design}

With the continuous development of science and technology Internet, interact design has more possibilities. But in the interactive design, there are still some laws to follow, which has the seven laws in the summary.

\section{Fitts'Law}

This is the mathematical model proposed by Paul Fitz in 1954 to predict the time required from any point to the target center. The most influential and far-reaching impacts are focused in human-computer interaction (HCI) and design. The change from starting menu to the beginning of the screen in Windows 8 is also the application of the law. 
Fig. 1 Fitts' Law

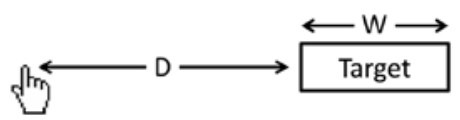

The content is: the time required to move from a starting position to a final goal is determined by two parameters. The distance to the target and the size of the target (D\&W in Figure 2) could be expressed as a mathematical formula time:

$$
T=\mathrm{a}+\operatorname{blog} 2(D / W+1)
$$

\section{Hick’s Law}

The more choices (n) a person faces, the longer the time (T) is needed. the reaction time is expressed as a mathematical formula. $T=\mathrm{a}+\mathrm{blog} 2(\mathrm{n})$. The more options in the interface, the more time a user makes a decision. For example, compared to 2 menus, each menu has 5 items; the user will be quicker to have 10 items from a menu to make a choice. Cock's law is applied to the design of menus and submenus in the software / web interface, and is also applied in mobile devices.

\section{Magical Number $7 \pm 2$ Rule}

George Miller made a quantitative study of short-term memory in 1956. He found that the best mind of the human mind can remember the information block containing 7 ( \pm 2 ) pieces, and the human mind begins to remember after memorizing 5-9 items. This finding is similar to the Skee law. The Magic Number $7 \pm 2$ Rule is often used in mobile application interaction design, such as the application of the tab will not exceed five.

Fig. 2 Magical Number $7 \pm 2$ Rule
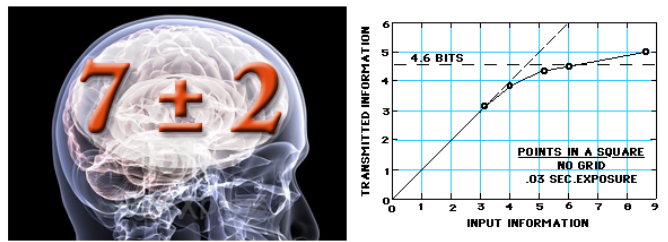

The Proximity Close Law, Tesler's Law(The law of conservation of complexity), Xinxiangzhongfu, the principle of error prevention and Occam's Razor principle (simple and effective principle) are the laws that interactive design should follow in the design of environmental guide system.

\section{A Brief Overview of Guide Systems Design}

"Guide" emphasizes the use of eyes and communication through the visual guide. It is rich in performance which can be expressed as signs, lights, maps, electronic screen and so on.

Communicate information about environmental space could be conveyed through elements such 
as graphics, text, shape, color, font, material, technology, and so on. From the nature of the guidance system, there are public guidance system and commercial guidance system. The public guidance system includes bus stations, railway stations and subways. The commercial guide is the visual logo aimed at profitable in the business environment, which are shown in Figure 4, 5, 6 below.

Fig.3 Shopping Mall Electronic Guide

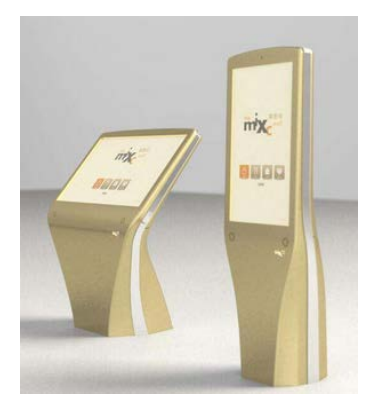

Fig.4 Car Tour Guide Logo

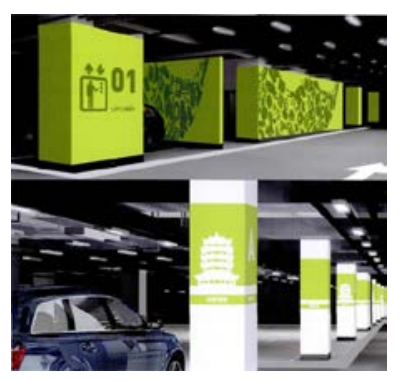

Fig.5 Parking Guide Logo

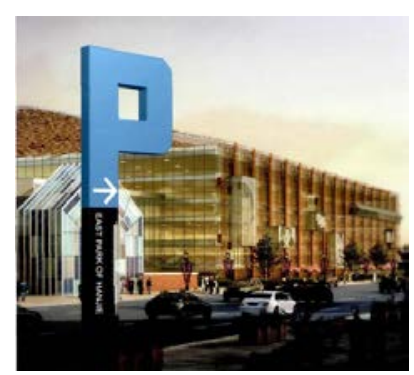

The main contents involved in the guide system design include text (shown in Figure 7), graphics (Figure 8), color and so on. The most important is that the actual environment should be combined to achieve the guide Effect, which could to provide convenience and help for people.

Fig. 6 Text Design of Guide System
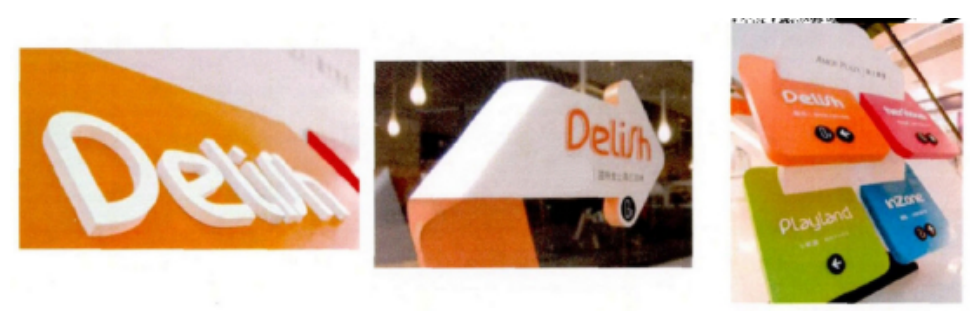
Fig.7 Graphic Design of Guide System

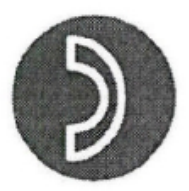

Telephone

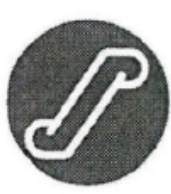

Escatator

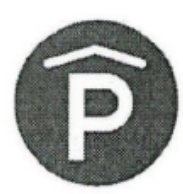

Parking

\section{Design of Interactive Guide System in Commercial Environment}

If guide systems could communicate information effectively in the complex business environment, it should stand out in the environment, assimilate into the environment and become one part of it. It can be seen that the complexity of commercial guides is much greater than that of other individual guided systems. At the same time, the current commercial competition is no longer the competition of goods quality, sales services and business show, but the process of expanding the whole process of business. Customers could fully feel safe, orderly, efficient and pleasure. Therefore it could win the customer's good psychological evaluation.

\section{The Framework of Interactive Design of Guide System}

Business environment guided system is an organic organization that consists of interacting, interconnected elements. According to this definition, its constituent elements are: people - people in the business environment, human behavior - the use of viewing systems or viewing, product using scenarios - business district, product integration technology - touch Screen multi-touch technology and the final product - guided system. So the interactive design of the guide system is actually around the first four basic elements of the design, a comprehensive analysis of their relationship. It finally designs the products of a harmonious coexistence. As shown in Figure 9.

Fig. 8 the Schematic Diagram of the Guide System Composition

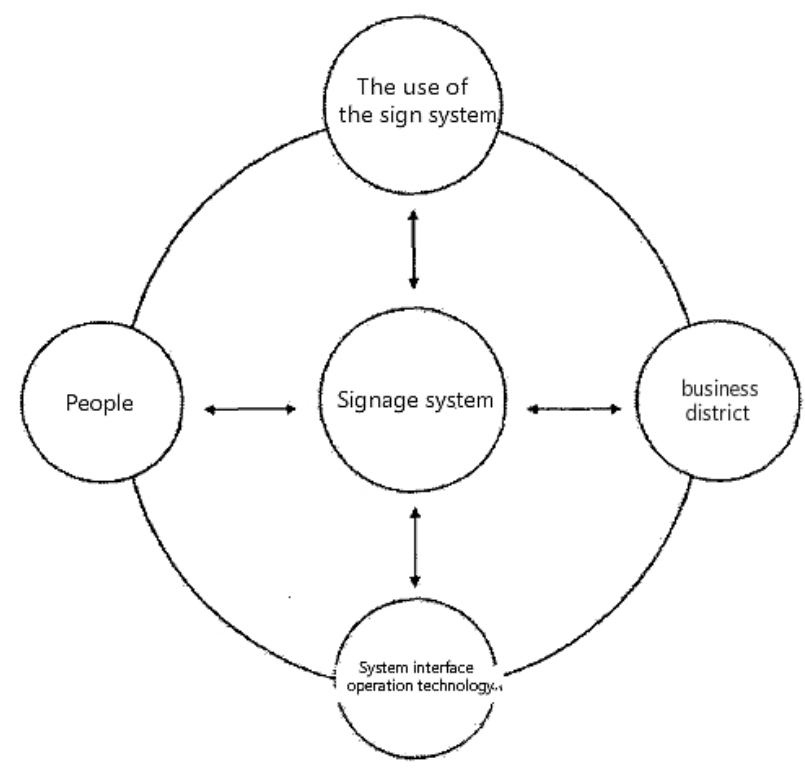

In the interactive design of business environment guided system, three methods are used, namely, general design method, user-centered interaction design method and interactive design method based on interpersonal interaction theory model. These three methods have their own focuses, in which the general design method emphasizes the product could meet the demand. 
User-centered interactive design focuses on people-centered thinking, concerning about the availability of products.

\section{Research on Design of Business Environment Guide System}

The design of the guide system will directly affect the entire building environment. So the primary task is to design its appearance in the guide system design. The need is to improve the attention of the plane shape and three-dimensional guide system design. Based on the light box, wall-mounted, three-dimensional structure, electronic guided system, combined with the business environment around the specific environment, the unique form shape is used to attract the attention of consumers and provide them with more information. At the same time, multi-touch, voice, body sensation and other high-tech are equipped with advanced touch screen electronic guided system to provide more interactive experience. Through the modeling design and rendering in the visual system, the actual display effect is shown ultimately. It is shown in Figure 10;

\section{Fig.9 The Actual Display of Commercial Environment Guide System}

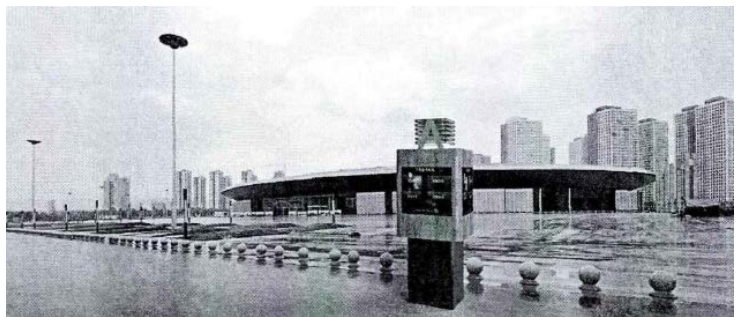

Second, we should also pay attention to the visual environment of the business environment visual interface and interactive prototyping design. The interaction between the visual systems is in the visual by the interface. Visual interface aesthetic and interactive use is the core of the entire design. For the business environment in the guide system, we strive to its fashionable design. So the interface should be rich to make Flash effect better. In the production of prototyping interaction, Axure RP is usually used, which can quickly and easily achieve results. Finally, when, Flash could have the exquisite effect in the high-fidelity design.

Finally, we should strengthen the evaluation of the interactive design of the guided system in the business environment from the aspects of user evaluation, heuristic evaluation and theoretical evaluation, so as to strengthen the interactive design of the guided system, optimize the reorganization of the interface structure of the guide system and the overall aesthetic design, The interactive process of human and habitual design could bring a more enjoyable experience for the user.

\section{Conclusion}

Technology opened up a new way of life for us. Rich material added color to our lives. As industrial designers and interactive designers, we should not only consider the form of beauty, but also our mission - to establish a bridge between science and technology and art, to provide users with warm things. With the status of user-driven products becoming more and more heavy, industrial designers are also facing the ideological changes. The industrial designers with interactive design ideas are the need of design, but also the needs of future industrial transformation and upgrading.

\section{References}

[1]Ning Lu. Research on the Design of Mobile Guide System in Commercial Environment [D]. Master's Degree Thesis of Southwest Jiaotong University,2015 
[2]Ge Yu. Research on the Interaction Design in Product Design [D]. Master 's Degree Thesis of Jilin University,2012

[3]Xiaoceng Ren. Analysis and Application of Guide System Design in Commercial Space Environment [J]. Journal of Xi'an Jiaotong University, 2013(3):48-51

[4]Yadan Xu. Research on the Application of Interactive Design in Conference Product System [D]. Guangdong University of Technology master 's degree thesis, 2011

[5]Huan Yang. Research on Interface Design of Mobile Internet for Mobile Phone [D]. Wuhan University of Technology doctoral dissertation, 2013

[6]Chenxin Hui. The Application of Interactive Design in the Design of Commercial Environment Guide System [D]. Master 's Degree Thesis of Taiyuan University of Technology, 2013

[7]Jingjing Ji. Research on the Interest Design of Commercial Space Guide System [D]. The Bachelor thesis of Xi'an University of Architecture and Technology, 2016 